\title{
Effects of Thyrotropin-Releasing Hormone and Its Analogs on Daytime Sleepiness and Cataplexy in Canine Narcolepsy
}

\author{
Seiji Nishino, Janis Arrigoni, Jeff Shelton, Takashi Kanbayashi, William C. Dement, and Emmanuel Mignot \\ Sleep Research Center, Stanford University School of Medicine, Palo Alto, California 94304
}

The therapeutic potential of thyrotropin-releasing hormone $(\mathrm{TRH})$ and TRH analogs in narcolepsy, a sleep disorder characterized by abnormal rapid eye movement (REM) sleep and daytime sleepiness, was examined using the canine model. The effects of $\mathrm{TRH}$ and the biologically stable $\mathrm{TRH}$ analogs CG3703, CG3509, and TA0910 on daytime sleep and cataplexy, a symptom of abnormal REM sleep, were assessed using polysomnographic recordings and the food elicited cataplexy test (FECT), respectively. CG3703 (100 and $400 \mu \mathrm{g} / \mathrm{kg}$, i.v.) and TA0910 (100 and $400 \mu \mathrm{g} / \mathrm{kg}$, i.v.) significantly increased wakefulness and decreased sleep in narcoleptic canines, whereas $\mathrm{TRH}(400$ and $1600 \mu \mathrm{g} / \mathrm{kg}$, i.v.) had no significant effect. TRH (25-1600 $\mu \mathrm{g} / \mathrm{kg}$, i.v.) and all three TRH analogs, CG3703 (6.25-

Narcolepsy is a disabling sleep disorder characterized by excessive daytime sleepiness and by abnormal manifestations of rapid eye movement (REM) sleep such as cataplexy and sleep paralysis (Parkes et al., 1975; Mitler et al., 1990; Aldrich, 1992; Guilleminault, 1994). Cataplexy is a sudden episode of muscle weakness precipitated by emotional excitation. The muscle weakness during cataplexy is similar to the muscle atonia during REM sleep, but it occurs abruptly during active wake instead of during REM sleep (Parkes et al., 1975; Mitler et al., 1990; Aldrich, 1992; Guilleminault, 1994). Narcolepsy occurs naturally in canines, and the disorder in this species presents behavioral, pharmacological, and electrophysiological similarities to the disorder in humans (for review, see Baker and Dement, 1985; Mignot et al., 1992; Nishino et al., 1994). Canine narcolepsy has been successfully used for a series of pharmacological studies that dissect the mode of action of currently used treatments for narcolepsy with the aim of developing better treatments for human narcolepsy (for review, see Nishino et al., 1994).

Human narcolepsy is currently treated with a combination of antidepressants for cataplexy and other REM-related symptoms and of amphetamine-like CNS stimulants for excessive daytime sleepiness (Parkes et al., 1975; Mitler et al., 1990; Thorpy and Goswami, 1990; Guilleminault, 1994). These treatments are often unsatisfactory because of unpleasant side effects and incomplete therapeutic efficacy, and new types of pharmacological interventions would be a welcome addition to currently available com-

Received Nov. 16, 1996; revised May 20, 1997; accepted May 27, 1997.

This work was supported by Cephalon and National Institutes of Health Grants NS-27710 and NS-23724. We thank Dr. M. Tafti for useful discussions, R. Sampathkumaran and the staff of the Department of Comparative Medicine for their technical assistance, and J. Riehl and A. De Sutter for their clerical assistance.

Correspondence should be addressed to Dr. Seiji Nishino, Stanford Sleep Disorders Research Center, 701 Welch Road, Suite 2226, Palo Alto, CA 94304.

Copyright (C) 1997 Society for Neuroscience $0270-6474 / 97 / 176401-08 \$ 05.00 / 0$
$400 \mu \mathrm{g} / \mathrm{kg}$, i.v., and 0.25-16 mg/kg, p.o.), CG3509 (25-1600 $\mu \mathrm{g} / \mathrm{kg}$, i.v.), and TA0910 (25-1600 $\mu \mathrm{g} / \mathrm{kg}$, i.v.), significantly reduced cataplexy in canine narcolepsy. These compounds did not produce any significant side effects during behavioral assays, nor did they alter free $T_{3}$ and $T_{4}$ levels in serum even when used at doses that completely suppressed cataplexy. Although more work is needed to establish the mode of action of TRH analogs on alertness and REM sleep-related symptoms, our results suggest a possible therapeutic application for $\mathrm{TRH}$ analogs in human sleep disorders.

Key words: thyrotropin-releasing hormone; narcolepsy; cataplexy; rapid eye movement sleep; deep sleep; light sleep

pounds (Parkes et al., 1975; Mitler, 1990; Thorpy and Goswami, 1990; Guilleminault, 1994).

Thyrotropin-releasing hormone (TRH), a tripeptidic hormone ( $p$-Glu-His-Pro- $\mathrm{NH}_{2}$ ) originally extracted from the hypothalamus, is now known to be distributed ubiquitously in the mammalian CNS (for review, see Jackson, 1982; Metcalf, 1982; Sharif, 1985; Griffiths and Bennett, 1987; Winokur et al., 1989) and to have multiple biological effects. TRH stimulates phosphatidyl inositol turnover at the pituitary level to activate synthesis and release of thyroid-stimulating hormone (TSH) and prolactin (for review, see Kolesnick and Gershengorn, 1985). TRH also has a variety of neuromodulatory effects not related to this pituitary impact. TRH stimulates cholinergic and monoaminergic turnover, depolarizes spinal motoneurons, enhances CNS arousal, modulates locomotor activity, regulates respiration, and modulates pain perception and epileptic threshold (for review, see Jackson, 1982; Metcalf, 1982; Sharif, 1985; Griffiths and Bennett, 1987; Winokur et al., 1989). Furthermore, TRH has been shown to have beneficial effects in depression (Prange et al., 1972), brain and spinal injuries (Faden, 1986), spinocerebellar degeneration (Sobue et al., 1983), and motoneuron diseases (Engel et al., 1983). Therapeutic indications of TRH for these diseases are, however, still very limited partially because of the pharmacokinetic profile of TRH. TRH is very unstable in biological tissues and is metabolized within minutes in the blood stream (Redding and Schally, 1972). Recently, several TRH analogs stabilized by modifications of either the $\mathrm{C}$ or $\mathrm{N}$ terminal of TRH have been introduced, making it possible to explore the therapeutic effects of TRH analogs in various neurological conditions further (Sharif et al., 1991; Yamamura et al., 1991).

In this study, the efficacy of TRH and of selected TRH analogs for the treatment of narcolepsy was explored using our canine model. The effects of TRH, CG3703, and TA0910 on sleep architecture were examined in narcoleptic canines using $6 \mathrm{hr}$ 


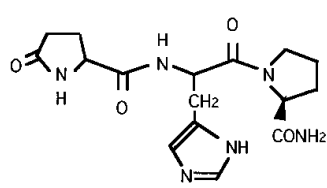

$\underline{T R H}$

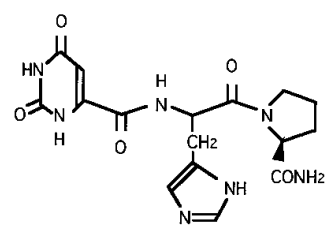

$\underline{\text { CG3509 }}$

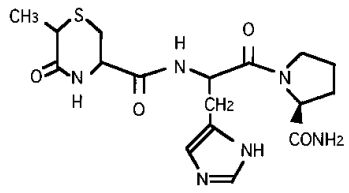

$\underline{\text { CG3703 }}$

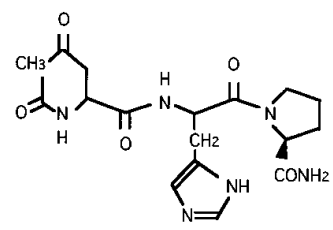

$\underline{T A 0910}$
Figure 1. Molecular structures of TRH and analogs. TRH is a tripeptidic hormone ( $p$-Glu-His-Pro- $\mathrm{NH}_{2}$ ) known to be very unstable in biological tissues. Several biologically stabilized TRH analogs (such as CG3703, CG3509, and TA0910) have been designed by modifying the $\mathrm{C}$ or $\mathrm{N}$ terminal of TRH.

daytime polygraphic recordings. The effects of TRH, CG3703, CG3509, and TA0910 on cataplexy were studied using the behavioral bioassay described previously, the food elicited cataplexy test (FECT) (Baker and Dement, 1985; Nishino et al., 1994).

\section{MATERIALS AND METHODS}

\section{Animals}

Dogs were housed in the Stanford University Department of Comparative Medicine in individual stainless steel cages $(1 \times 1.8 \mathrm{~m})$. All experiments were performed in strict accordance with the guidelines described in the National Institutes of Health Guide for the Care and Use of Laboratory Animals. Dogs were fed daily at 9 A.M. and exposed to a $12 \mathrm{hr}$ light/dark cycle. Six narcoleptic Doberman pinschers (65.1 \pm 11.4 months old, mean \pm SEM) were used for cataplexy testing and for serum $\mathrm{T}_{3}$ and $\mathrm{T}_{4}$ measurements. A total of four implanted narcoleptic (48.2 \pm 12.4 months old) and four implanted control Doberman pinschers $(33.6 \pm 14.4$ months old) were used for the polysomnographic study.

\section{Drugs}

TRH was purchased from Sigma (St. Louis, MO). CG3703 and CG3509 (manufactured at Grünenthal, $\mathrm{GmbH}$, Germany) were obtained from Cephalon (West Chester, PA). TA0910 was obtained from Tanabe Seiyaku (Toda-shi, Saitama, Japan). The structures of TRH and of the analogs of TRH are presented in Figure 1. The dose ranges of TRH and of the analogs of TRH used for this study were selected from the results of pilot assessments. The inactive low dose $(0.40 \mathrm{mg} / \mathrm{kg}$, i.v. $)$ of each compound was initially administered to two narcoleptic dogs, and changes in behavior (including cataplexy), heart rate, blood pressure, and rectal temperature were monitored for $2 \mathrm{hr}$. When no noticeable changes were observed except in cataplexy, a drug dose that was four times higher than the original dose was administered, and the same assessment was repeated until cataplexy was completely suppressed. The four highest doses among the doses tested were selected for the dose-response studies for cataplexy testing, and the two highest doses were used for polygraphic recordings. The highest dose was used for measurements of free $\mathrm{T}_{3}$ and $\mathrm{T}_{4}$ levels in serum. All compounds were dissolved in vehicle $(5 \%$ dextrose containing 5\% ethanol) at $1 \mathrm{ml} / 10 \mathrm{~kg}$ body weight and were administered intravenously to narcoleptic dogs through the cephalic vein. All drug solutions were prepared freshly each experimental day. Oral drug administration was also performed for one of the TRH analogs, CG3703. In this protocol, the drug powder was mixed with a small amount of wet dog food that was fed to the dogs.

\section{Six hour daytime recordings}

The effects of TRH, CG3703, and TA0910 on the sleep of four narcoleptic Doberman pinschers were assessed using a polygraphic monitor (Grass, eight-channel recorder) connected to the animals. The effect of one of the TRH analogs CG3703 on sleep was also examined in four control Doberman pinschers. The doses of TRH used were 400 and 1600 $\mu \mathrm{g} / \mathrm{kg}$ intravenously, and those of CG3703 and TA0910 were 100 and 400 $\mu \mathrm{g} / \mathrm{kg}$ intravenously. The animals were implanted with electroencephalogram (EEG), electro-oculogram (EOG), and electromyogram (EMG) electrodes. Detailed protocols for surgical implantation of the electrodes have been described previously (Nishino et al., 1995). Dogs were kept in a recording chamber $(3 \times 3 \mathrm{~m})$ with the lights on, and they were observed from an adjoining room through a two-way mirror and a video camera. Six hours of polygraphic data were collected after each injection, starting between 9:30 and 10:30 A.M. In all cases, animals were kept 1 entire day in the recording room before the actual data collection was initiated to avoid a possible "first day effect" secondary to the animal's habituating to the new environment. The order of the injections (vehicle, low dose, and high dose) was randomized for each dog, and at least $2 \mathrm{~d}$ passed between any two drug vehicle injection sessions to allow for drug washout. A Latin square design was used so that any residual drug effects would cancel out when the drug effect of each dose was analyzed.

\section{Sleep stage scoring}

Polygraphic records are scored in $30 \mathrm{sec}$ epochs for active wake, drowsy state, light sleep, deep sleep, REM sleep, and cataplexy. Scoring criteria for each behavioral state were based on Kaitin et al. (1986) with minor modifications (Nishino et al., 1995). These criteria are based on frequency and amplitude patterns of two cortical tracings (frontofrontal and frontoparietal), EMG and EOG, together with notes on behavior. Briefly, wake includes all episodes with low-voltage mixed frequency tracings in which the EMG is not inhibited. During this stage, canines lie down, sit up, stand, or walk, and the eyes are open. The drowsy state is scored when the animal lies quietly with its eyes partially open or closed and when the cortical EEG shows trains of relatively slow waves $(5-7 \mathrm{~Hz})$ without the development of sleep spindles. Synchronous waves at $4-7 \mathrm{~Hz}, 50-100 \mu \mathrm{V}$, appear on a background of low-voltage fast activity. The EMG amplitude shows a moderate decrease from wakefulness. In light sleep, canines are relaxed with prone posture, EEG patterns are more synchronous and of higher amplitude than in the previous stage, and sleep spindles (10-14 $\mathrm{Hz}$ ) and/or $\mathrm{K}$ complexes (in frontoparietal tracing) must be present. Deep sleep is scored when high-amplitude slow waves $(<4 \mathrm{~Hz})$ constitute $>20 \%$ of a $30 \mathrm{sec}$ epoch. REM sleep is scored when a lowvoltage mixed frequency EEG tracing is observed together with REMs and with a significant drop in EMG activity. Canines are relaxed with prone posture, and muscle twitches may be, but are not always, seen. The previous two epochs must have been scored as sleep (light sleep, deep sleep, or REM sleep) for an epoch to be designated REM sleep. REM sleep was considered to have ended when the EMG increased or when sleep spindles and/or $\mathrm{K}$ complexes started to appear on the recording. An additional scoring category, cataplexy, must be considered in narcoleptic animals. Cataplexy is scored when an abrupt drop in EMG during wakefulness is observed. If standing, the dogs will often fall; the back legs are especially likely to buckle. Occasionally, the dog may maintain a standing posture, but all movement must cease and the head must droop to score cataplexy in this case. The EEG pattern is low-voltage mixed frequency; REMs are sometimes seen; and muscle twitches may be, but are not always, seen. The previous two epochs had to be wake, drowsy state, or cataplexy for an epoch to be scored cataplexy. A cataplectic attack was considered to have ended when the EMG returned to its previous amplitude or when spindles (light sleep) started to appear.

\section{Cataplexy testing}

Drug effects on cataplexy were studied under either dose-response or time course designs. In both cases, FECTs (Baker and Dement, 1985; Nishino et al., 1994) were used to quantify cataplexy. This test uses the fact that the excitement caused by the presentation of food can trigger cataplexy in narcoleptic canines. Briefly, 12 pieces of food are placed in a circle, and the experimenter records the number and duration of cataplectic attacks that occur while the animal eats them. The time required for the dog to eat all of the pieces of food (elapsed testing time), an indirect measure of the total time spent in cataplexy, is also recorded. This is done twice for each data point. 
Dose-response studies. Six narcoleptic dogs were used for all doseresponse studies. In the intravenous dose-response design, FECTs are first performed to measure baseline cataplexy levels. Dogs are then injected intravenously with the lowest dose of TRH or the analogs that is selected from the pilot studies. A routine of FECTs and of cardiovascular and temperature measurements is then repeated at $30 \mathrm{~min}$ intervals with the dose increasing fourfold after each round of testing. The doses of TRH, CG3509, and TA0910 used were 25, 100, 400, and $1600 \mu \mathrm{g} / \mathrm{kg}$, whereas those of CG3703 were $6.25,25,100$, and $400 \mu \mathrm{g} / \mathrm{kg}$. For the CG3703 oral administration dose-response study, the dogs first received a low dose of CG3703 $(0.0625 \mathrm{mg} / \mathrm{kg}$, p.o.). The same routine testing was then repeated at $2 \mathrm{hr}$ intervals with the dose increasing $(0.25,1,4$, and 16 $\mathrm{mg} / \mathrm{kg}$ ) after each round of testing.

Heart rate, blood pressure, and rectal temperature are recorded after each FECT duplicate testing period as described in Nishino et al. (1990). Behavioral side effects are also monitored throughout the experiment simply by observing the animals during FECTs.

Time course study of the oral administration of CG3703. After two baseline FECT tests and the usual cardiovascular and temperature measurements at -1 and $0 \mathrm{hr}$, the dogs received a single dose of CG3703 (16 mg/kg, p.o.). Routine testings were then repeated $0.5,1,2,3,6,12$, and $24 \mathrm{hr}$ after drug administration.

\section{Measurements of free $T_{3}$ and $T_{4}$ levels in serum}

Serum $\mathrm{T}_{3}$ and $\mathrm{T}_{4}$ levels were measured in six narcoleptic Doberman pinschers after the intravenous administration of TRH or TRH analogs. In this protocol, $3 \mathrm{ml}$ of blood was collected twice for baseline measurements before drug administration $(-0.5 \mathrm{hr}$ and $-1 \mathrm{~min})$. TRH (1600 $\mu \mathrm{g} / \mathrm{kg})$, CG3703 (400 $\mu \mathrm{g} / \mathrm{kg})$, CG3509 (1600 $\mu \mathrm{g} / \mathrm{kg})$, or TA0910 (400 $\mu \mathrm{g} / \mathrm{kg}$ ) was then injected intravenously, and blood samples were collected $0.5,1,2,4$, and $8 \mathrm{hr}$ after drug administration. Fifty microliters of serum were then used to measure free $T_{3}$ and $T_{4}$ levels using ${ }^{125} \mathrm{I}$ radioimmunoassay (RIA) kits (INCSTAR, Stillwater, MN). Intra-assay reliabilities for $\mathrm{T}_{3}$ and $\mathrm{T}_{4}$ measurements were 4.8 and $4.3 \%$, respectively. All comparative measurements for $\mathrm{T}_{3}$ and $\mathrm{T}_{4}$ were performed in the same set of RIAs, and every sample was measured in duplicate.

\section{$\left[{ }^{3} H\right]$ Methyl-TRH binding experiments}

The affinities of TRH and TRH analogs for canine TRH receptors were studied in vitro using $\left[{ }^{3} \mathrm{H}\right]$ methyl-TRH binding (New England Nuclear; specific activity of $84.3 \mathrm{Ci} / \mathrm{mol}$ ) according to the methods described by Ogawa et al. (1981). The cortex of normal Doberman pinschers was used for this study. Briefly, frozen tissue samples are homogenized in $20 \mathrm{vol}$ of ice-cold Tris- $\mathrm{HCl}\left(50 \mathrm{~mm}, \mathrm{pH} 7.6\right.$, at $\left.25^{\circ} \mathrm{C}\right)$ per weight of tissue using a Polytron tissue grinder. Homogenates are then centrifuged at $15,000 \times$ $g$ for $20 \mathrm{~min}$ at $4^{\circ} \mathrm{C}$, and the pellets are washed twice by resuspension and recentrifugation as described above. The final pellet is resuspended in $300 \mathrm{vol}(2 \mathrm{mg}$ of cortex in $900 \mu \mathrm{l}$ of buffer/tube) of ice-cold Tris-HCl (50 $\mathrm{mM}, \mathrm{pH} 7.6$, at $\left.25^{\circ} \mathrm{C}\right)$ containing bacitracin $(50 \mu \mathrm{g} / \mathrm{ml})$. Saturation binding assays were performed at equilibrium with 10-12 dilutions of $\left[{ }^{3} \mathrm{H}\right]$ methyl-TRH $(0.5 \mathrm{nM}-20 \mathrm{nM})$. Total binding and nonspecific binding were measured in duplicate. Specific binding was measured as the excess over blanks (in the presence of $100 \mu \mathrm{M}$ TRH). Competition experiments using $5.2 \mathrm{nM}\left[{ }^{3} \mathrm{H}\right]$ methyl-TRH $\left(K_{\mathrm{d}}\right.$ value for $\left[{ }^{3} \mathrm{H}\right]$ methyl-TRH obtained from saturation experiments) were performed with displacing agent concentrations ranging from $10^{-10}$ to $10^{-3} \mathrm{M}$. Tissue incubation $\left(0^{\circ} \mathrm{C}\right.$ for $3 \mathrm{hr}$ ) was terminated by rapid vacuum filtration with subsequent rinsing (12 ml of ice-cold TRIS buffer) using a Brandel M48-R cell harvester and Whatman $\mathrm{GF} / \mathrm{C}$ glass fiber filter paper presoaked with $50 \mathrm{ml}$ of polyethylimine $(0.1 \%)$. Radioactivity retained on the filters was measured in $5 \mathrm{ml}$ of Cytoscint (ICN Radiochemicals, Irvine, CA) by liquid scintillation spectrometry (Beckman LS3801). Saturation experiments and competition experiments for each compound were repeated three to four times, and the binding data $\left(K_{\mathrm{d}}, K_{\mathrm{i}}\right.$, and $\left.B_{\max }\right)$ were analyzed using the weighted, nonlinear, least-squares curve-fitting program LIGAND (Munson and Rodbard, 1980) as modified by McPherson et al. (1985). Data were analyzed with assumptions of single and multiple independent binding site models by evaluating multiple files (three to four) simultaneously.

\section{Statistics}

All statistical analyses were performed on a personal computer using SYSTAT (Systat, Evanston, IL). Significant $(p)$ changes over the course of the dose-response, time course, and sleep-recording studies were calculated using nonparametric Friedman's ANOVA. For FECT exper- iments, when drug effects on cataplexy were statistically significant $(p<$ $0.05)$, the $\mathrm{ED}_{50}(\mu \mathrm{g} / \mathrm{kg}$, p.o. or i.v.) was calculated by nonlinear regression analysis (Quasi-Newton procedure) on a dose-response curve using the equation $E=E_{\max } /\left(1+\left(\mathrm{ED}_{50} /\right.\right.$ dose $\left.)\right)$ described in Pliska (1987), where $E_{\max }$ was considered to be the total suppression of cataplexy.

\section{RESULTS}

\section{Effects of TRH, CG3703, and TA0910 on sleep and wakefulness}

The effects of TRH (400 and $1600 \mu \mathrm{g} / \mathrm{kg}$, i.v.), CG3703 (100 and $400 \mu \mathrm{g} / \mathrm{kg}$, i.v.), and TA0910 (100 and $400 \mu \mathrm{g} / \mathrm{kg}$, i.v.) on sleep in four narcoleptic animals are presented in Figure 2. CG3703 and TA0910, two biologically stable TRH analogs, dose-dependently increased wakefulness over a $6 \mathrm{hr}$ recording period. The effects of these compounds were most prominent during the first $2 \mathrm{hr}$ and decreased (for TA0910) or disappeared (for CG3703) between 2 and $6 \mathrm{hr}$ after the injection. In two narcoleptic animals, the high dose of TA0910 (400 $\mu \mathrm{g} / \mathrm{kg}$, i.v.), but not of CG3703, induced moderate shivering (determined by the EMG trace) when the animals were in the drowsy state. TRH also dose-dependently increased wakefulness and reduced slow wave sleep (SWS) for the initial $2 \mathrm{hr}$, but these effects did not reach statistical significance (Fig. 2). TRH (400 and $1600 \mu \mathrm{g} / \mathrm{kg}$, i.v.) did not induce shivering.

The effects of CG3703 were also examined in four control Doberman pinschers. As reported previously (Nishino et al., 1995; Shelton et al., 1995), control animals spend more time awake than narcoleptic dogs do during baseline conditions [67.1\% $(n=4)$ vs $43.9 \%(n=12)$ of the total $6 \mathrm{hr}$ recording period]. In these control animals, CG3703 also dose-dependently increased wakefulness $(p<0.05)$; the percentages of time spent in wakefulness during $6 \mathrm{hr}$ recording periods were 74.1 and $84.9 \%$ after intravenous administrations of CG3703 at 100 and $400 \mu \mathrm{g} / \mathrm{kg}$, respectively. In two of the control animals tested, moderate shivering (determined by the EMG trace) was observed when the animals were in the drowsy state. However, less intense shivering was also noticed in the baseline (vehicle) session in these animals.

\section{Effects of TRH, CG3703, CG3509, and TA0910 on canine cataplexy}

The dose-responses of TRH, CG3703, CG3509, and TA0910 on cataplexy are shown in Figure 3. All compounds dosedependently reduced canine cataplexy, and a nearly complete suppression of this symptom was observed at high doses (Fig. 3). A dose-response curve was drawn for each compound, and the potency $\left(\mathrm{ED}_{50}\right)$ for the anticataplectic effect was estimated. The order of potency was found to be TA0910 (69 nmol $/ \mathrm{kg}$, i.v. $)>$ CG3703 (170 nmol/kg, i.v.) > TRH (440 nmol/ $\mathrm{kg}$, i.v.) > CG3509 (609 nmol/ kg, i.v). No significant changes in heart rate, blood pressure, or rectal temperature were observed. Furthermore, no noticeable behavioral side effects were observed during these experiments.

Oral administration of CG3703 also dose-dependently reduced cataplexy (Fig. 4). After administration of the highest dose (cumulative dose, $21.3 \mathrm{mg}$ ), a complete suppression of cataplexy was observed in most animals. When a single oral dose of CG3703 (16 $\mathrm{mg} / \mathrm{kg}$ ) was administered, the maximal anticataplectic effect occurred between 3 and $6 \mathrm{hr}$ and lasted $>12 \mathrm{hr}$.

\section{Effects of TRH and the analogs of TRH on free $\mathrm{T}_{3}$ and $\mathbf{T}_{\mathbf{4}}$ levels in serum}

To study whether the anticataplectic or alerting effects of TRH and TRH analogs are related to their effects on thyroid function, free $T_{3}$ and $T_{4}$ levels in serum were also measured after the 
TRH (0-2 hrs)

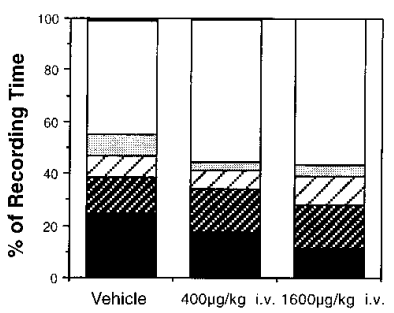

CG3703 (0-2 hrs)

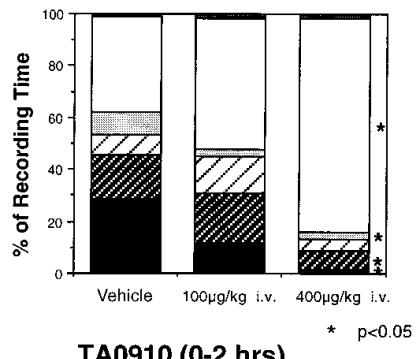

TA0910 (0-2 hrs)

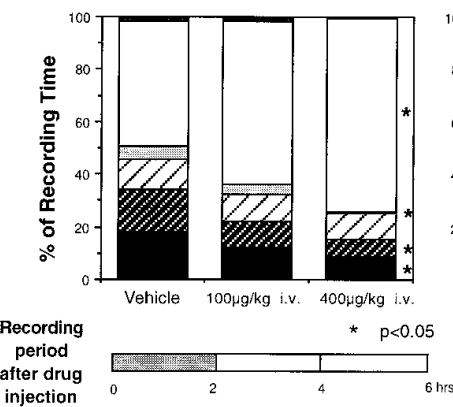

TRH (2-4 hrs)

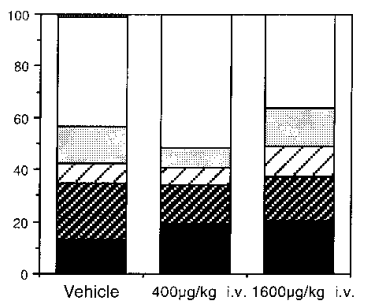

CG3703 (2-4 hrs)

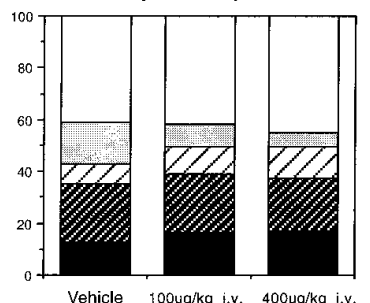

TA0910 (2-4 hrs)

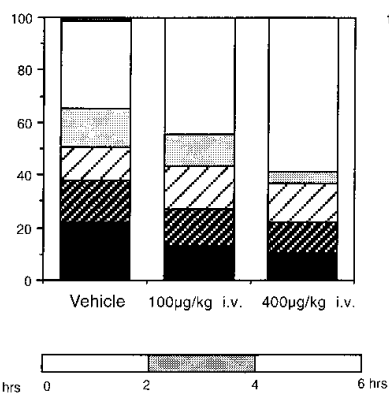

TRH (4-6 hrs)

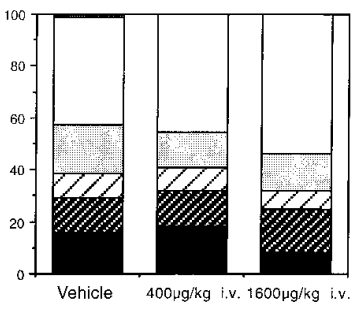

CG3703 (4-6 hrs)

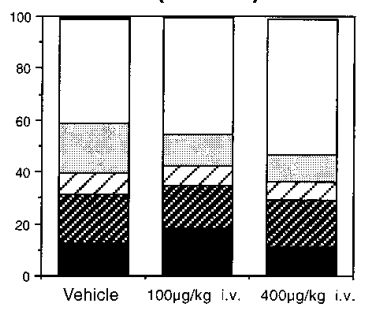

TA0910 (4-6 hrs)

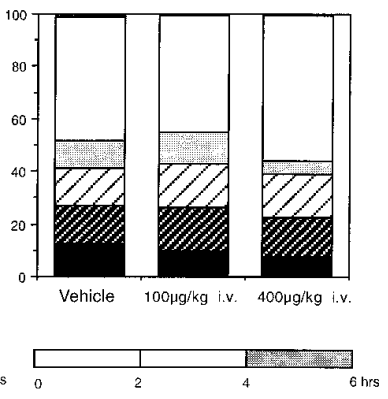

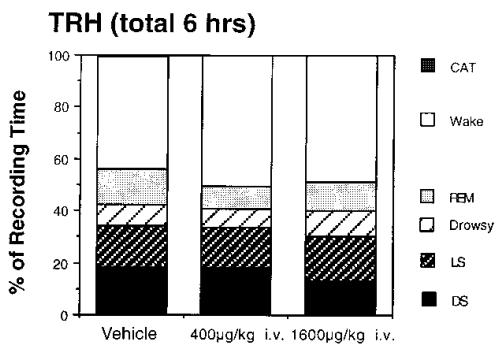

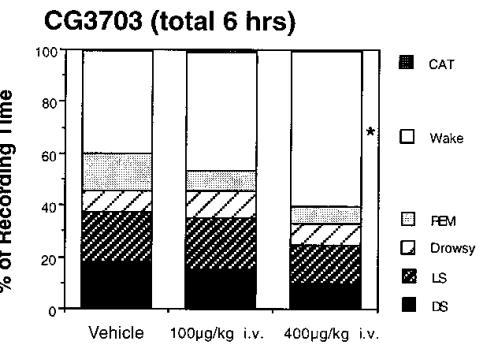

* $p<0.05$

TA0910 (total 6 hrs)

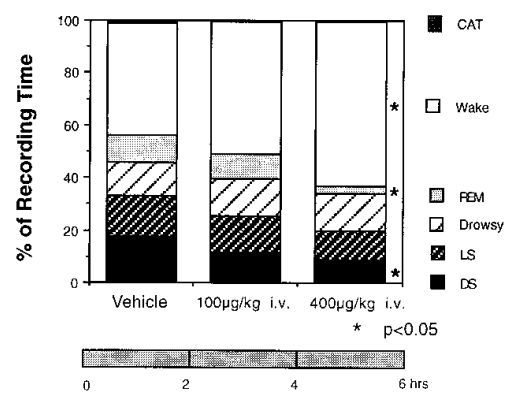

Figure 2. Effects of TRH, CG3703, and TA0910 on sleep stages in narcoleptic dogs. Vehicle, TRH (400 or $1600 \mu \mathrm{g} / \mathrm{kg}$, i.v.), CG3703 (100 or $400 \mu \mathrm{g} / \mathrm{kg}$, i.v.), or TA0910 (100 or $400 \mu \mathrm{g} / \mathrm{kg}$, i.v.) was injected in four narcoleptic Doberman pinschers, and polygraph data were recorded for 6 hr. Sleep stage effects are shown for every $2 \mathrm{hr}$ period and for the total $6 \mathrm{hr}$ recording session. TRH had no significant effects on any sleep parameters. In contrast, CG3703 and TA0910, two biologically stabilized TRH analogs, significantly decreased sleep (for the first 2 hr) and increased wakefulness in a dose-dependent manner $\left({ }^{*} p<0.05\right.$, by nonparametric Friedman's ANOVA). The effect of CG3703 on sleep was also assessed in control animals in which it was found to increase wakefulness significantly and dose-dependently (data given in Results). CAT, Cataplexy; REM, REM sleep; $L S$, light sleep; $D S$, deep sleep.

administration of TRH or the analogs of TRH. The administration of TRH and TRH analogs at doses that effect cataplexy and sleep and wake patterns did not significantly modify free $\mathrm{T}_{3}$ and $\mathrm{T}_{4}$ levels for $8 \mathrm{hr}$ (Fig. 5). This result suggests that the effects of TRH analogs on thyroid function do not mediate the effects of the compounds on daytime sleepiness and cataplexy in canine narcolepsy.

\section{In vitro receptor binding affinities of TRH analogs do not correlate with in vivo effects}

Saturation experiments indicated that $\mathrm{TRH}$ receptors in canine cortex membrane exhibit a single high-affinity binding site $\left(K_{\mathrm{d}}=\right.$ $5.2 \mathrm{nM})$. TRH and all TRH analogs tested displaced $100 \%$ of the specific binding with different affinities (values of $K_{\mathrm{i}}$ ). The in vitro affinity of each compound is listed in Table 1 together with the in vivo anticataplectic and alerting potency. The results demonstrate that the in vitro affinity does not correlate well with the in vivo potency for the anticataplectic or alerting effects of the compounds.

\section{DISCUSSION}

Human narcolepsy is currently treated unsatisfactorily using a combination of antidepressants for cataplexy and other REM- related symptoms and of amphetamine-like CNS stimulants for excessive daytime sleepiness (Parkes et al., 1975; Mitler et al., 1990, 1994; Thorpy and Goswami, 1990; Guilleminault, 1994). Because TRH is reported to have both CNS stimulant and antidepressant effects (Prange et al., 1972; Griffiths and Bennett, 1987), TRH may have an alternative therapeutic indication in narcolepsy. In the current study, we therefore assessed the effects of TRH and newer stabilized TRH analogs on daytime sleepiness and cataplexy in the canine model of narcolepsy.

Daytime polygraphic recordings in narcoleptic canines have been used successfully to assess the potency and efficacy of various reference stimulant compounds, such as D-amphetamine, on excessive daytime sleepiness (Shelton et al., 1995). TRH and TRH analogs are well known to antagonize barbiturate- or ethanol-induced sleep time in several animal species, including dogs (Havlicek et al., 1976; Hernandez et al., 1987; Arnold et al., 1991). Few systematic polygraphic studies have, however, been done previously that explore the effects of TRH on sleep or vigilance. One study reported the effects of TRH on nighttime sleep in humans (Horikawa, 1978), but the dose of TRH used (2 $\mathrm{mg} /$ person, p.o.) was very low, and no significant effects were observed. In the current study, we found that TRH had little 

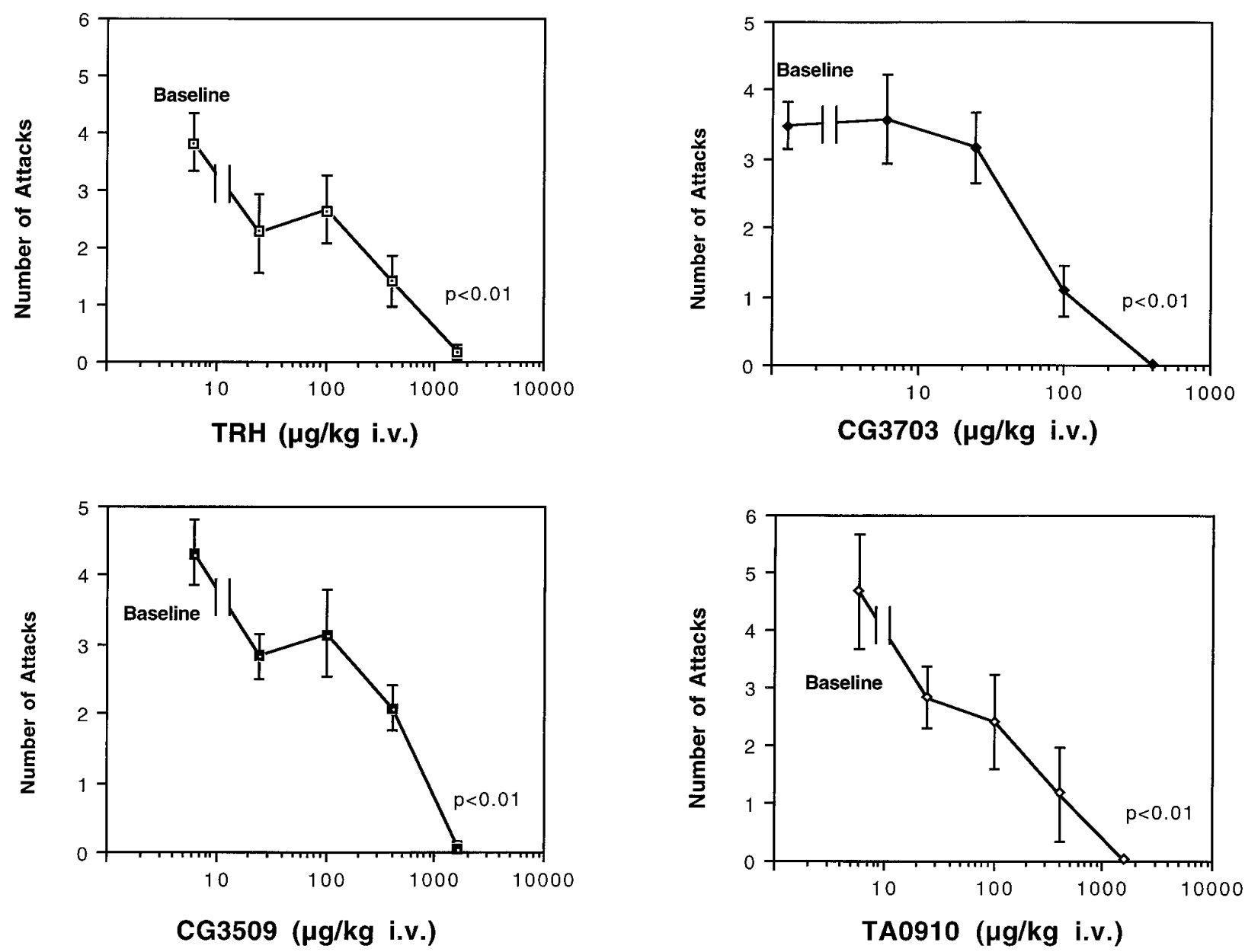

Figure 3. Effects of TRH and TRH analogs on canine cataplexy. The effects of TRH and the analogs of TRH on canine cataplexy were examined using FECTs. TRH and TRH analogs all dose-dependently reduced canine cataplexy ( ${ }^{*} p<0.01$, by nonparametric Friedman's ANOVA).

effect on alertness in narcoleptic animals. Two stabilized TRH analogs (CG3703 and TA0910), however, significantly reduced SWS and REM sleep in this animal model. These effects were dose-dependent and time-dependent (Fig. 2) and were observed in both control and narcoleptic animals. The effects of CG3703 and TA0910 at $400 \mu \mathrm{g} / \mathrm{kg}$ were quite robust and comparable with the effects of D-amphetamine at $150 \mu \mathrm{g} / \mathrm{kg}$ or of modafinil at 10 $\mathrm{mg} / \mathrm{kg}$ (Shelton et al., 1995), the compounds currently used for the treatment of excessive daytime sleepiness in human narcolepsy. The vigilance-enhancing effects of TRH analogs were not associated with any effects on thyroid function. Moderate shivering during polygraphic recordings was observed in some narcoleptic and control animals after TA0910 and CG3703 administrations, respectively. The occurrence of intense shivering in the drowsy state after the administration of TRH analogs may have contributed to the reduction of SWS. However, a significant sleep-reducing effect was also observed in animals who did not show any shivering during polygraphic recordings (determined by the EMG trace). Our results therefore suggest that newer TRH analogs may be useful as vigilance-enhancing agents for the treatment of excessive daytime sleepiness in narcolepsy.

TRH analogs also had significant effects on cataplexy (Fig. 3). At the highest doses of each compound, cataplexy was completely suppressed in most animals. Antidepressants are the most com- monly used anticataplectic agents, but these compounds have many side effects such as drowsiness, dry mouth, urinary retention, and impotence (Parkes et al., 1975; Mitler et al., 1990, 1994; Thorpy and Goswami, 1990; Guilleminault, 1994). Antidepressants are known to reduce REM sleep potently (Polc et al., 1979), and this REM suppressant effect is probably involved in mediating the anticataplectic properties of these agents (Nishino et al., 1997). TRH has also been reported to have antidepressant properties, and our polygraphic studies showed that CG3703 and TA0910 significantly reduced REM sleep. It is therefore likely that the anticataplectic properties of TRH analogs are secondary to their REM suppressant effects.

Although electrophysiological recordings demonstrated that some animals exhibited shivering when drowsy, we did not observe any noticeable side effects such as changes in general behavior, appetite, rectal temperature, heart rate, or blood pressure during other experimental protocols. Thus, the side effect profile of these compounds was rather favorable. Serum $\mathrm{T}_{3}$ and $\mathrm{T}_{4}$ measurements also did not change significantly after drug administration, thus suggesting that the anticataplectic and alerting effects of TRH and the analogs of TRH are mediated by neuromodulatory CNS properties and not by indirect effects on the thyroid axis. In vivo potency of TRH analogs on cataplexy or alertness, however, did not correlate well with in vitro $\mathrm{TRH}$ 


\section{Dose-response}

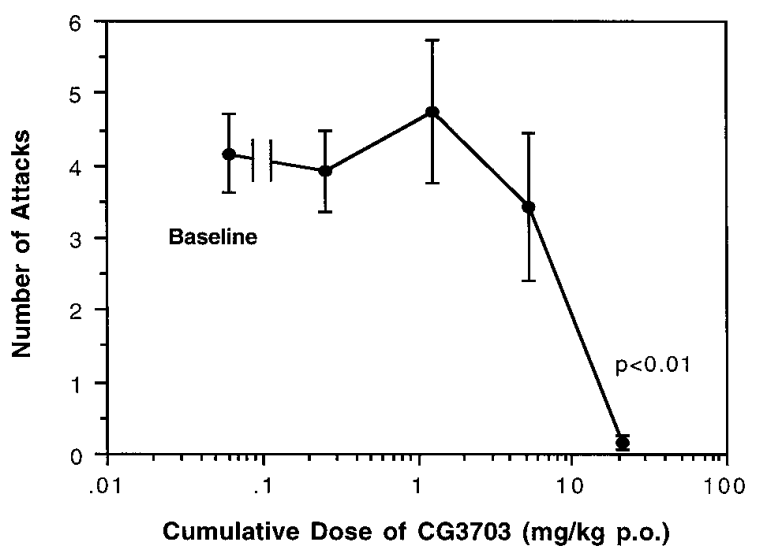

Time course

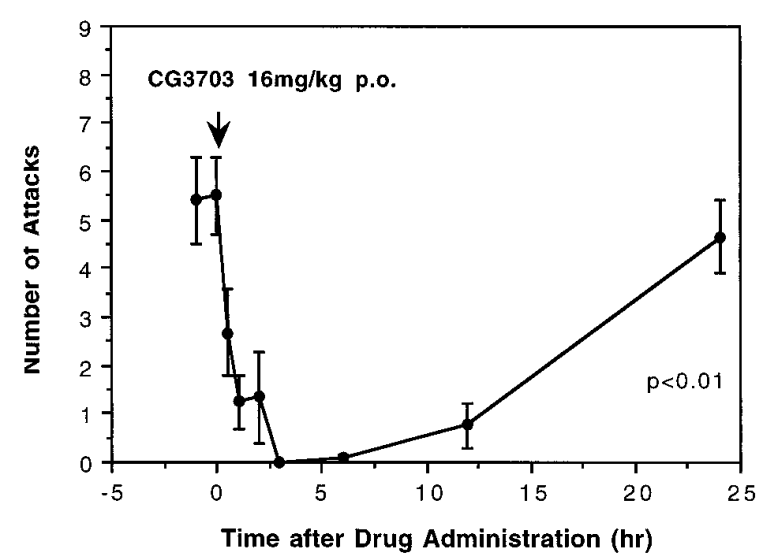

Figure 4. Effects of oral administration of CG3703 on canine cataplexy. Oral administration of one of the TRH analogs, CG3703, significantly reduced canine cataplexy (FECTs) in a dose- and time-dependent manner $\left({ }^{*} p<0.01\right.$, by nonparametric Friedman's ANOVA).

receptor binding affinity results, especially the results for TRH itself. This discrepancy may be explained by the fact that TRH is very unstable in the blood stream (Redding and Schally, 1972), and thus TRH has little central effect when administered peripherally.

Pharmacological studies using the canine narcolepsy model have demonstrated that both monoaminergic and cholinergic tone are important for the regulation of sleepiness and abnormal REM sleep in narcolepsy (for review, see Nishino et al., 1994, 1997). Both the adrenergic and cholinergic systems are critically involved in the control of cataplexy (Mignot et al., 1989, 1993; Nishino et al., 1990, 1993a,b, 1995; Reid et al., 1994a,b), whereas dopaminergic systems are important in the regulation of alertness (Nishino et al., 1996, 1997). Large numbers of experiments suggest that TRH has modulatory effects on these neurotransmitters. TRH is reported to enhance central noradrenaline turnover, and this effect may mediate the antidepressant effect of TRH (Keller et al., 1974; Reigle et al., 1974). It has also been reported that TRH analogs increase dopamine release in brain slices (Sharp et al., 1982), and in vivo experiments suggest that dopaminergic systems are involved in the stimulating effects of TRH on locomotor activity (Yamamura et al., 1991). Finally, a cholinergic mediation of the antagonism of TRH effects on pentobarbital-induced sleep

\section{T3 levels}

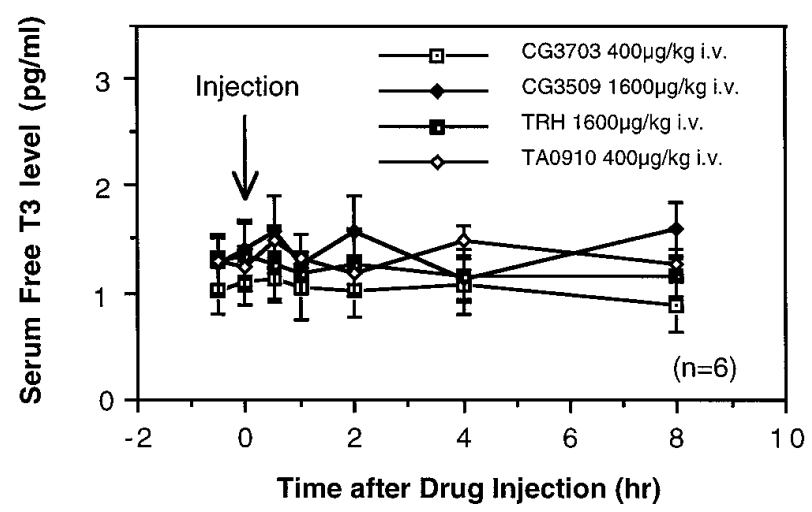

T4 levels

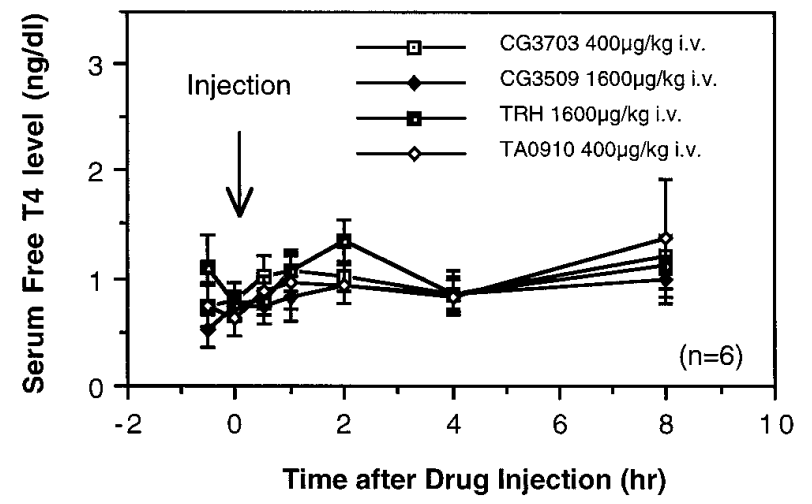

Figure 5. Effect of TRH and analogs on free $\mathrm{T}_{3}$ and $\mathrm{T}_{4}$ levels in the serum of narcoleptic dogs. A single intravenous administration of TRH or analogs at doses that completely suppress cataplexy did not significantly modify serum $\mathrm{T}_{3}$ or $\mathrm{T}_{4}$ levels $(p>0.05$, by nonparametric Friedman's ANOVA).

Table 1. In vivo effects on canine cataplexy and in vitro affinities of TRH and TRH analogs for canine TRH receptors

\begin{tabular}{lllr} 
& $\begin{array}{l}\text { Effect on cataplexy } \\
\mathrm{ED}_{50}(\mathrm{nmol} / \mathrm{kg}, \\
\text { i.v. })\end{array}$ & $\begin{array}{l}\text { Effect on alert- } \\
\text { ness }(\% \text { change } \\
\text { from baseline) }\end{array}$ & $\begin{array}{r}\text { Affinity } \\
K_{\mathrm{i}}(\mathrm{nM})\end{array}$ \\
\hline TA0910 & $69^{*}$ & Increase $\left(+46.7^{*}\right)$ & 397 \\
CG3703 & $170^{*}$ & Increase $\left(+52.7^{*}\right)$ & 245 \\
TRH & $440^{*}$ & Increase $(+17.6)$ & 30 \\
CG3509 & $609^{*}$ & Not tested & 3481
\end{tabular}

All compounds significantly suppressed canine cataplexy in a dose-dependent manner. Drug effects on cataplexy are reported as $\mathrm{ED}_{50}$ values (nmol/ $\mathrm{kg}$, i.v.), drug doses producing $50 \%$ of the maximal effect. The values included were estimated by nonlinear regression analysis using the equation, $E=E_{\max } /\left[1+\left(\mathrm{ED}_{50} /\right.\right.$ dose $\left.)\right]$. Effects on alertness are displayed as percentage of changes from the baseline session in time spent in wake during a $6 \mathrm{hr}$ recording period after a $400 \mu \mathrm{g} / \mathrm{kg}$ intravenous drug administration. Statistically significant effects $(p<0.05)$ are indicated with an asterisk. Affinities for canine TRH receptors were determined by $\left[{ }^{3} \mathrm{H}\right]$ methyl-TRH binding, as described in Materials and Methods.

has also been reported (Kalivas and Horita, 1979; Miyamamoto et al., 1982). All or some of these neuromodulatory effects of TRH may mediate the effects of TRH on cataplexy and alertness.

TRH may also impact the symptoms of narcolepsy through spinal mechanisms. TRH potently depolarizes spinal motoneurons (Nicoll, 1977; Ono and Fukuda, 1982), the same neurons that 
are normally tonically inhibited during the atonia of REM sleep (Glenn, 1978; Morales and Chase, 1978) and presumably of cataplexy. TRH may thus directly act on spinal motoneurons and thereby reduce cataplexy.

In conclusion, our study suggests that TRH analogs may have therapeutic effects on human narcolepsy. Oral administration of one of the TRH analogs (CG3703) was found to reduce cataplexy for several hours, and this compound could even be a candidate for drug development. The mode of action of TRH analogs on cataplexy and alertness and the involvement of TRH in the pathophysiology of narcolepsy, however, still remain to be explored.

\section{REFERENCES}

Aldrich MS (1992) Narcolepsy. Neurology 42:34-43.

Arnold R, Klingberg F, Schäker W (1991) Systemically applied thyrotropin-releasing hormone (TRH) modifies spontaneous behavior of rats. Biomedica Biochimica Acta 50:1217-1224.

Baker TL, Dement WC (1985) Canine narcolepsy-cataplexy syndrome: evidence for an inherited monoaminergic-cholinergic imbalance. In: Brain mechanisms of sleep (McGinty DJ, Drucker-Colin R, Morrison A, Parmeggiani PL, eds), pp 199-233. New York: Raven.

Engel WK, Siddique T, Nicoloff J (1983) Effect on weakness and spasticity in amyotrophic lateral sclerosis of thyrotropin-releasing hormone. Lancet 2:73-75.

Faden AI (1986) Neuropeptide and central nervous system injury: clinical implications. Arch Neurol 45:501-504.

Glenn LL (1978) Membrane potential of spinal motoneurons during natural sleep in cats. Sleep 1:199-204

Griffiths EC, Bennett GW (1987) Clinical applications of thyrotropinreleasing hormone. Clin Sci 73:449-457.

Guilleminault C (1994) Narcolepsy syndrome. In: Principles and practice of sleep medicine (Kryger MH, Roth T, Dement WC, eds), pp 549-561. Philadelphia: Saunders.

Havlicek V, Rezek M, Friesen H (1976) Somatostatin and thyrotropinreleasing hormone: central effect on sleep and motor system. Pharmacol Biochem Behav 4:455-459.

Hernandez DE, Meyer RE, Irving PE, Crane SW (1987) Reversal of pentobarbital-induced narcosis by thyrotropin-releasing hormone (TRH) in dogs. Pharmacol Res Commun 19:567-577.

Horikawa S (1978) Effect of a single oral dose of TRH on all night sleep polygraphs of normal healthy subjects. Noha To Kinzenzu (Tokyo) 6:99-107.

Jackson IMD (1982) Thyrotropin-releasing hormone. N Engl J Med 306:145-155.

Kaitin KI, Kilduff TS, Dement WC (1986) Sleep fragmentation in genetically narcoleptic dogs. Sleep 9:116-119.

Kalivas PW, Horita A (1979) Thyrotropin-releasing hormone: central site of action in antagonism of pentobarbital narcosis. Nature 278:461-463.

Keller HH, Bartholini G, Pletscher A (1974) Enhancement of cerebral noradrenaline turnover by thyrotropin-releasing hormone. Nature 248:528-529.

Kolesnick RN, Gershengorn MC (1985) Thyrotropin-releasing hormone and the pituitary: new insights into the mechanisms of stimulated secretion and clinical usage. Am J Med 79:729-739.

McPherson GA (1985) Analysis of radioligand binding experiments: a collection of computer programs for IBM PC. J Pharmacol Methods 14:213-228.

Metcalf G (1982) Regulatory peptides as a source of new drugs: the clinical prospects for analogs of TRH which are resistant to metabolic degradation. Brain Res Rev 4:389-408.

Mignot E, Guilleminault C, Bowersox S, Fruhstorfer B, Nishino S, Maddaluno J, Ciaranello R, Dement WC (1989) Central alpha-1 adrenoceptor subtypes in narcolepsy-cataplexy: a disorder of REM sleep. Brain Res 490:186-191.

Mignot E, Guilleminault C, Dement WC, Grumet C (1992) Genetically determined animal models of narcolepsy, a disorder of REM sleep. In: Genetically defined animal models of neurobehavioral dysfunction (Driscoll P, ed), pp 90-110. Cambridge, MA: Birkäuser Boston.

Mignot E, Renaud A, Nishino S, Arrigoni J, Guilleminault C, Dement WC (1993) Canine cataplexy is preferentially controlled by adrenergic mechanisms: evidence using monoamine selective uptake inhibitors and release enhancers. Psychopharmacology (Berl) 113:76-82.

Mitler MM, Hajdukovic R, Erman M, Koziol JA (1990) Narcolepsy. J Clin Neurophysiol 7:93-118.

Mitler MM, Aldrich MS, Koob GF, Zarcone VP (1994) Narcolepsy and its treatment with stimulants. Sleep 17:352-371.

Miyamamoto M, Nagai Y, Narumi S, Saji Y, Nagawa Y (1982) TRH and its novel analog (DN-1417): antipentobarbital action and involvement of cholinergic mechanisms. Pharmacol Biochem Behav 17:797-806.

Morales FR, Chase MH (1978) Intracellular recording of lumbar motoneuron membrane potential during sleep and wakefulness. Exp Neurol 62:821-827.

Munson PJ, Rodbard D (1980) LIGAND; a versatile computerized approach for characterization of ligand-binding system. Anal Biochem 107:220-239.

Nicoll RA (1977) Excitatory action of TRH on spinal motoneurons. Nature 265:242-243.

Nishino S, Haak L, Shepherd H, Guilleminault C, Sakai T, Dement WC, Mignot E (1990) Effects of central alpha-2 adrenergic compounds on canine narcolepsy, a disorder of rapid eye movement sleep. J Pharmacol Exp Ther 253:1145-1152.

Nishino S, Arrigoni J, Shelton J, Dement WC, Mignot E (1993a) Desmethyl metabolites of serotonergic uptake inhibitors are more potent for suppressing canine cataplexy than their parent compounds. Sleep 16:706-712.

Nishino S, Fruhstorfer B, Arrigoni J, Guilleminault C, Dement WC, Mignot E (1993b) Further characterization of the alpha-1 receptor subtype involved in the control of cataplexy in canine narcolepsy. J Pharmacol Exp Ther 264:1079-1084.

Nishino S, Reid M, Dement WC, Mignot E (1994) Neuropharmacology and neurochemistry of canine narcolepsy. Sleep 17:S84-S92.

Nishino S, Tafti M, Reid MS, Shelton J, Siegel JM, Dement WC, Mignot E (1995) Muscle atonia is triggered by cholinergic stimulation of the basal forebrain: implication for the pathophysiology of narcolepsy. J Neurosci 15:4806-4814.

Nishino S, Mao J, Sampathkumaran R, Honda K, Dement WC, Mignot E (1996) Differential effects of dopaminergic and noradrenergic uptake inhibitors on EEG arousal and cataplexy of narcoleptic canines. Sleep Res 25:317.

Nishino S, Mao J, Sampathkumaran R, Shelton J, Dement WC, Mignot E (1997) Adrenergic, but not dopaminergic, uptake inhibition reduces REM sleep and cataplexy concomitantly. Sleep Res 26:445.

Ogawa N, Yamawaki Y, Kuroda H, Ofuji T, Itoga E, Kito S (1981) Discrete regional distributions of thyrotropin releasing hormone (TRH) receptor binding in monkey central nervous system. Brain Res 205:169-174.

Ono H, Fukuda H (1982) Ventral root depolarization and spinal reflex augmentation by a TRH analog in rat spinal cord. Neuropharmacology 21:739-744.

Parkes JD, Baraitser M, Marsden CD, Asselman P (1975) Natural history, symptoms and treatment of the narcoleptic syndrome. Acta Neurol Scand 52:337-353.

Pliska V (1987) Dose-response models: similarity with population growth dynamics. Trends Pharmacol Sci 8:50-52.

Polc P, Schneeberger J, Haefely W (1979) Effects of several centrally active drugs on the sleep-wakefulness cycle of cats. Neuropharmacology 18:259-267.

Prange A, Wilson I, Lara P, Alltop L, Breese G (1972) Effects of thyrotropin-releasing hormone in depression. Lancet 2:999-1002.

Redding TW, Schally AV (1972) On the half life of thyrotropin-releasing hormone in rats. Neuroendocrinology 9:250-256.

Reid MS, Tafti M, Geary J, Nishino S, Siegel JM, Dement WC, Mignot E (1994a) Cholinergic mechanisms in canine narcolepsy. I. Modulation of cataplexy via local drug administration into pontine reticular formation. Neuroscience 59:511-522.

Reid MS, Tafti M, Nishino S, Siegel JM, Dement WC, Mignot E (1994b) Cholinergic regulation of cataplexy in canine narcolepsy in the pontine reticular formation is mediated by M2 muscarinic receptors. Sleep 17:424-435.

Reigle TG, Avni J, Platz PA, Schildkraut JJ, Plotnikoff NP (1974) Norepinephrine metabolism in the rat brain following acute and chronic administration of thyrotropin-releasing hormone. Psychopharmacologia 37:1-6.

Sharif N (1985) Diverse roles of thyrotropin-releasing hormone in brain, pituitary, and spinal cord function. Trends Pharmacol Sci 6:119-122. 
Sharif NA, To ZP, Whiting RL (1991) Analogs of thyrotropin-releasing hormone (TRH): receptor affinities in brain, spinal cords, and pituitaries of different species. Neurochem Res 16:95-103.

Sharp T, Bennett GW, Marsden CA (1982) Thyrotropin-releasing hormone analogues increase dopamine release from slices of rat brain. J Neurochem 39:1763-1766.

Shelton J, Nishino S, Vaught J, Dement WC, Mignot E (1995) Comparative effects of modafinil and amphetamine on daytime sleepiness and cataplexy of narcoleptic dogs. Sleep 18:817-826.

Sobue I, Takayanagi T, Nakanishi T, Tsubaki T, Uono M, Kinoshita M, Igata A, Miyazaki M, Yoshida M, Ando K, Maruyama S, Mitsuma T,
Nihei N, Sakuma A, Kato K (1983) Controlled trial of thyrotropin releasing hormone tartrate in ataxia of spinocerebellar degenerations. J Neurol Sci 61:235-248.

Thorpy MJ, Goswami M (1990) Treatment of narcolepsy. In: Handbook of sleep disorders (Thorpy MJ, ed), pp 235-258. New York: Dekker.

Winokur A, Manaker S, Krieder M (1989) TRH and TRH receptors in the spinal cord. Ann NY Acad Sci 553:314-324.

Yamamura M, Kinoshita K, Nakagawa H, Ishida R (1991) Pharmacological study of TA-0910, a new thyrotropin-releasing hormone (TRH) analog: involvement of the DA system in the locomotor stimulating action of TA-0910. Jpn J Pharmacol 55:57-68. 